\title{
How to talk to someone with an "untreatable" lifelong condition
}

\section{Nick Wood}

Nick Wood suggests ways that healthcare professionals can help people with conditions that have no obvious treatment. For series information contact Rosamund Snow, patient editor, rsnow@bmj.com.

I live with a painful condition that no one wants to talk about and relatively few seem to research.

It is also a condition that took a long and traumatic period to diagnose, working towards a diagnosis by exclusion, which resulted in many months of fear and turmoil as to whether I might have the dreaded prostate cancer.

There was little relief though in finally being told, after months of invasive investigations, that I had chronic prostatitis or chronic pelvic pain syndrome (CP/CPPS), because when I asked about treatment options I was told (with a shrug): "Not much is truly effective with your condition currently I'm afraid."

"What's the usual course of illness then? How can I get better?" I asked desperately.

The urology registrar I was seeing replied: "Well, it might burn itself out, anywhere from four years to . . . perhaps never." He shrugged again on that last word and the consultation was over.

Having already had many months of incessant pelvic pain and urinary difficulties that resulted in limited sleep, I left that appointment in tears, clutching some out of date handouts the registrar had printed from the web. Although I had avoided crying in front of the registrar, I found myself (usually a very private and contained person) weeping helplessly in public as I collected a pain prescription from the pharmacy. It was as if a life sentence of suffering had been given to me, with a lack of empathy and dismissal that made me feel very alone.

As time went on I often felt I was a "heartsink" patient. No general practitioner seemed to want to listen to my story, and a few perhaps even doubted my experiences. (I also had the sense that they felt that little else could be done, so what was the point of my "complaining" or even continuing to attend medical appointments?)

But there were things they could have done, as I realised over time. This came home to me when I finally found a urologist who had been through a bout of acute prostatitis. It was a huge relief when he told me about his own experience and how hard it was for him to accept there was little he could do to help me, given he knew how awful and painful it must be to deal with this illness on an ongoing basis, with no idea about when, if ever, it might resolve. Having contact with a medical professional who acknowledged my suffering and his limited ability to help, but who respected me and made time to listen to my account, was a turning point for me in terms of my medical management. This respectful listening and support is not limited to having had personal experience of the illness you are treating-I have since found a sympathetic GP who has no personal experience of the illness but a listening ear and a non-dismissive attitude. I now attend a specialist pain clinic that he referred me to, with some hope I can get a handle of sorts on this condition.

At diagnosis, then, how might the doctor of my dreams have answered my questions?

"What's the usual course of illness then? How can I get better?"

"Well, I'm afraid we don't really know; prognosis varies greatly. There are some evolving guidelines you can look at here; once you've had a chance to read them we can discuss them if it would help. In the meantime, though, what other support do you have to manage this terrible condition? And what else can I do to help you with this?'

There is something strangely reassuring about doctors who admit to limits of knowledge where limits exist-it makes them more human and present in the moment. Being pointed towards the latest developing guidelines would have helped too because it would have alerted me to the fact that the doctor was keeping up to date with this condition, and the belief that the evidence is evolving is somewhat reassuring. Finally, being invited back to carry on the conversation would have reassured me that I was not being abandoned to manage an "incurable" condition on my own; this would have been reinforced by other questions exploring current external support.

I am one of an estimated $15 \%$ of men with this difficult and painful condition. There's some truth in the stereotype that men don't talk enough—we need to talk more and raise awareness, galvanising further research to combat this debilitating illness. Many men, and perhaps some doctors, may feel embarrassed about the symptoms of CP/CPPS, but we need to take the lid off this condition. And all we ask from our doctors is honesty, care, and support-so if in doubt about how your patient feels at the end of a session, ask (and it's up to us male patients to tell).

Competing interests: I have read and understood BMJ policy on declaration of interests and declare the following interests: none. 


\section{The bottom line}

- You should be open about the limits of your knowledge, but you can make a huge difference by checking for current and ongoing guidelines, making referrals, and helping us to find external support. I was helped most by referral for chronic pain and mood management, potential sexual therapy for sexual dysfunction difficulties, and the discovery of online groups for patient peer support

- Even when you cannot cure us, your continuing guidance and support are crucially important to patient morale and engagement, especially during multiple investigations that are potentially confusing and traumatic

\section{Suggested reading}

Charon R. Narrative medicine: honoring the stories of illness. Oxford University Press, 2008

Frank A. The wounded storyteller: body, illness, and ethics. 2nd ed. University of Chicago Press, 2013

Hunter KM. Doctors' stories: the narrative structure of medical knowledge. Princeton University Press, 1991

Kleinman A. Illness narratives: suffering, healing and the human condition. Basic Books, 1989

Parks T. Teach us to sit still: a sceptic's search for health and healing. Vintage, 2011

Prostatitis Expert Reference Group. Chronic prostatitis and chronic pelvic pain syndrome: a new consensus guideline. 2014. http:// prostatecanceruk.org/for-health-professionals/best-practice/guidelines/chronic-prostatitis-and-chronic-pelvic-pain-syndrome

Prostate Cancer UK. Prostatitis. http://prostatecanceruk.org/prostate-information/other-prostate-problems/prostatitis-1

British Prostatitis Support Association. www.bps-assoc.org.uk 